\title{
EROTISMO E REPRESENTAÇÃO DO CORPO NEGRO EM TERRA NEGRA, DE CRISTIANE SOBRAL
}

\author{
Henrique Marques Samyn \\ (UERJ) \\ https://orcid.org/0000-0002-2624-3487
}

\section{RESUMO}

Este artigo pretende apresentar uma leitura de Terra negra, de Cristiane Sobral, por intermédio de uma análise do erotismo e da representação do corpo negro nos poemas "Sagrada esperança", "Alforria", "Eu falo", "Luxúria", "Miradouros", "Quem sou eu” e "Papo reto". Argumenta-se que, na poesia de Sobral, esses temas assumem significados específicos informados por raça e gênero, o que faculta o questionamento de estereótipos e a construção de um discurso poético inovador.

PALAVRAS-CHAVE: Cristiane Sobral, poesia de autoria feminina, poesia negro-brasileira

\section{EROTICISM AND REPRESENTATION OF THE BLACK BODY IN TERRA NEGRA, BY CRISTIANE SOBRAL}

\section{ABSTRACT}

This article aims to provide a reading of Terra negra, by Cristiane Sobral, by an examination of eroticism and the representation of the black body in the poems "Sagrada esperança", "Alforria", "Eu falo", "Luxúria", "Miradouros", "Quem sou eu", and "Papo reto". It is argued that, in Sobral's poetry, these themes assume specific meanings informed by race and gender, which allows the questioning of stereotypes and the construction of an innovative poetry.

KEYWORDS: Cristiane Sobral, black female authorship, AfroBrazilian literature 
Meu objetivo, neste artigo, é tecer considerações em torno de alguns dos poemas recolhidos em Terra negra, de Cristiane Sobral, com ênfase em composições que abordam temas associados ao erotismo e, extensivamente, à afetividade e à representação do corpo negro. Conquanto motivos eróticos apareçam de forma recorrente na literatura brasileira contemporânea, seu tratamento na literatura negro-brasileira ${ }^{1}$, sobretudo em obras de autoria feminina, apresenta particularidades que demandam uma análise atenta ao modo como nela se manifestam elementos decorrentes de uma intersecção de gênero e raça - sem que isso implique, evidentemente, um desprezo dos aspectos estéticos e retóricos próprios da linguagem poética.

No que diz respeito ao corpus escolhido, vale observar que Terra negra reúne a produção lírica mais recente de Cristiane Sobral, artista negra de evidente relevância no atual cenário cultural brasileiro. Nascida na zona oeste do Rio de Janeiro e radicada em Brasília, Cristiane Sobral é atriz - foi a primeira negra a se formar em Interpretação Teatral pela Universidade de Brasília -, tendo concebido e protagonizado diversos espetáculos, alguns premiados ${ }^{2}$. Data de 2000 sua inserção no meio literário, por intermédio da publicação no vigésimo terceiro volume dos Cadernos Negros, colaborando também em outros volumes ${ }^{3}$. Desde então, Cristiane Sobral vem percorrendo uma sólida trajetória como escritora, atriz e dramaturga, consolidando-se como figura referencial no cenário artístico e cultural brasileiro. Propor uma leitura de alguns dos poemas coligidos em Terra negra significa, portanto, atualizar a fortuna crítica de uma intelectual negra de reconhecida importância.

Pode-se perceber que o amor ocupa um lugar central em Terra negra já pela epígrafe da obra, extraída de um dos mais potentes textos de bell hooks, "Vivendo de amor". Cristiane Sobral cita precisamente um trecho que aborda a força transformadora do amor sobre as mulheres negras: uma força capaz de levá-las a alterar as estruturas sociais, a somar forças

1 Sobre o conceito de literatura negro-brasileira, cf. Cuti (2010; em particular o capítulo 3: "Negro ou afro não tanto faz").

2 Podem-se citar: "Uma Boneca no Lixo", premiado em 1999 pelo Governo do Distrito Federal e dirigido por Hugo Rodas; "Dra. Sida" (Ministério da Saúde, 2000); e I, II e III Ciclo de Dramaturgia Negra, realizados em Brasília e Porto Alegre. Cf. o levantamento de Vera Lúcia da Silva Sales Ferreira (2014).

3 Cristiane Sobral colaborou nos seguintes volumes dos Cadernos Negros: 23, 24, $25,29,30,32,33,34,35,36$ e 38 . 
para lutar contra o genocídio do povo preto, a sonhar um novo futuro a partir da transformação do presente. $\mathrm{O}$ fato de esse fragmento anteceder a matéria lírica, na condição de epígrafe, opera sinalizando uma abertura e desvelando o motivo central da obra; não obstante, importa perceber que há nisso o resgate de um conceito que opera à maneira de um fundamento. Assim, já se evidencia que o tratamento do temário amoroso em Terra negra assume um sentido específico: não se trata de meramente revisitar um motivo tradicional da literatura, mas de propor uma abordagem do tema que, sem negligenciar a potência estética do discurso lírico, contemple sua significância para a experiência própria das mulheres negras.

Encontramos essa força renovadora do amor tematizada em "Sagrada esperança" (SOBRAL, 2017, p. 26-27):

Eu te amei no primeiro instante

Antes que minha consciência chegasse

senti a minha carne rasgando por dentro

Certa dilatação no peito

$\mathrm{O}$ sangue jorrando nas veias, acelerado

Nunca houve alguém como você

Enxerguei como se não pudesse ver

o que poderíamos construir juntos

Eu te amei em cada centímetro da sua pele negra

Entregando o meu corpo

Como quem oferece flores na madrugada

Você surgiu em intenso negrume

Rasgando minha carne trêmula

Tomando posse de tudo que já era seu

Imaginei cada senzala

Cada Casa Grande de onde fugimos

$\mathrm{O}$ porto onde nos separamos

Os filhos levados ao nascer

Com sofreguidão

Eu te amei como se não houvesse mais tempo

Na urgência dos nossos desesperos

Almas saudosas em um tempo apressado

Amantes, alados, corações errantes

Vivendo o átimo presente 
Derramado em cada gota de amor.

Lidas isoladamente, as duas primeiras estâncias da composição sugerem nela não haver mais do que o resgate do motivo do amor à primeira vista, aliás um dos topoi mais comuns no imaginário amoroso ocidental - presente, por exemplo, no discurso atribuído a Aristófanes no Banquete de Platão, quando este figura os seres humanos primitivos como formas andróginas circulares posteriormente cindidas por Zeus, de modo que aquele que encontra sua outra metade é imediatamente tomado pelo afeto e pelo amor (2013, p. 109-112); ou na célebre descrição do enamoramento de Dante Alighieri por Beatrice Portinari, na Vita nuova (1973, p. 3-4). Na primeira estrofe do poema de Cristiane Sobral, a alusão à emergência de um afeto que precede a consciência enfatiza o imediatismo desse processo, cuja intensidade é evidenciada pela minuciosa descrição de seus aspectos físicos - o que, justamente por realçarsalientar efeitos corporais, antecipa as experiências eróticas descritas mais adiante. A segunda estrofe descreve a elaboração cognitiva desse enlevamento, que se traduz na certeza da singularidade da relação estabelecida e em sua projeção temporal pelo sujeito lírico, à maneira de uma dilatação do momento presente.

A subversão do topos se efetiva na terceira estrofe, que encerra a racialização do corpo amado - de modo a deslocar aquele lugar-comum de uma tradição literária (pretensamente) universal para inscrevê-lo em um âmbito particular, desconhecido (quando não recusado, mediante discursos hipersexualizantes) pela representação do mundo fundamentada em valores brancocêntricos. Esse deslocamento inscreve a composição de Cristiane Sobral em um campo temático próprio da literatura de autoria negra - cultivado, especificamente no que diz respeito à literatura negro-brasileira de autoria feminina, por Lívia Natália, Elizandra Souza, Cuti e Akins Kinté, entre outros ${ }^{4}$.

A hiperbólica construção presente no verso que abre essa terceira estância - "Eu te amei em cada centímetro da sua pele negra" - demanda atenção, visto que, para além de conceder ao corpo negro o apanágio de objeto amoroso, eleva qualitativamente a afetividade ao absoluto. Em outras palavras, isso significa que o corpo do amado se constitui como merecedor da máxima afeição precisamente enquanto corpo racializado, o que inverte a dinâmica imposta pela ordem racista. Isso é reiterado pela alusão, no quarto verso, ao "intenso negrume", cujo poder sobre a subje-

4 Para uma amostra contemporânea, cf. Kintê; Cuti, 2015. 
tividade lírica - descrito no ato de rasgar a "carne trêmula" - é positivamente celebrado.

A potência decorrente dessa relação amorosa - que, como ressaltei, encontra sua condição de possibilidade na racialização dos corpos - se evidencia na quarta estrofe, em que a experiência erótica enseja a evocação de um conjunto de elementos historicamente vinculados à opressão do corpo negro. Ao imaginar "cada senzala" e "cada Casa Grande", recuperando fugas outrora ocorridas, e as separações impostas entre amantes, pais e filhos, a subjetividade lírica enfatiza em que medida a afirmação positiva do afeto que enlaça corpos racializados como negros confronta uma dinâmica de poder erigida para inviabilizar expressões afetivas similares. A referência à fuga de espaços que materializavam a opressão escravista, conquanto ocorrida em tempos passados, alude metaforicamente à possibilidade de evasão de âmbitos e dinâmicas que atualizam estruturas de poder coloniais; remete, por conseguinte, à luta hodierna por liberdade, enquanto resistência às opressões que ainda cerceiam as manifestações afetivas de corpos negros. A subjetividade lírica se reconhece, portanto, como legatária de processos históricos - e disposta a fazer de seu amor um gesto emancipatório, que ganha sentido à luz da incessante trajetória de luta do povo preto.

Não obstante, a certeza de que essa emancipação não se pode efetivar sem enfrentamentos se evidencia nos versos finais da composição, que explicitam a urgência que subjaz à experiência amorosa. O sôfrego amar, "como se não houvesse mais tempo", é assim alimentado pela ânsia por libertação; e a errância dos corações dispostos a viver "o átimo presente" decorre do significado intrínseco a um evento que subverte uma história marcada pela opressão racista.

A percepção do aspecto político inerente a qualquer manifestação da afetividade negra que assume uma direção emancipatória pode também ser percebida em “Alforria” (SOBRAL, 2017, p. 39-40):

Não vou mais cuidar do senhor

Agora quero um tempo comigo

Paquerar minhas carnes no espelho

Arreganhar os olhos com rímel

Sair

Não vou mais cuidar do senhor

Eu tenho outras coisas pra fazer 
Liberta do exercício de cuidar de outrem

talvez conheça meu verdadeiro valor

Não vou mais cuidar do senhor

Quero tomar um banho gostoso

Esfregar a consciência

Sem temer qualquer indecência

Não vou mais cuidar do senhor

Abaixo o discurso maniqueísta

A ilusão não pode sair mais cara que o sonho

Prepare-se meu senhor

Antes de sair

Quero gozar

Desfrutar a cama imensa

Serei muito mais do que você pensa

Este é um lema para manter

Terei tempo pra ser e não ser

Não vou mais cuidar pelo senhor

A vida é curta para não desfrutar do amor.

Vale notar como, já no primeiro verso, a subjetividade poética ostensivamente recusa a autoridade senhorial, preterindo-a em favor de gestos que manifestam um autocuidado - dispender o tempo consigo mesma, paquerar-se diante do espelho, ornamentar-se com rímel - e afastando-se do confinamento imposto, algo, aliás, referido com notável força retórica por um sucinto verso dissilábico: "Sair". Desse modo, essa estrofe de abertura encerra um movimento que, a partir de um ato negativo, constrói as condições de possibilidade para a autoafirmação, o que é demarcado pelo contraste entre os advérbios que abrem o primeiro e o segundo versos: sem o "não" que rejeita a dinâmica de poder imposta pelo senhor, o "agora" jamais aconteceria.

A importância da recusa é recuperada nas três estâncias seguintes, mediante uma repetição do verso inicial, o que tem múltiplos efeitos: há nisso tanto uma ênfase na soberania alcançada pelo eu lírico quanto a constituição de um leitmotiv que desenvolve o título da composição. Ademais, em termos retóricos, essa repetição resgata o ato negativo como uma espécie de fundo sobre o qual a subjetividade lírica pode afirmar, positivamente, a liberdade conquistada. De fato, os horizontes abertos pela 
alforria (ressalte-se: autoconcedida) se evidenciam na priorização de si, o que enseja a possibilidade da autodescoberta como consequência de uma atenção que não mais se limitará ao alheio - a libertação do "exercício de cuidar de outrem", o que faculta à subjetividade lírica o conhecimento de seu "verdadeiro valor". É quando emerge o caminho para o despertar erótico, perceptível na alusão ao banho que, já liberto do decoro imposto pela autoridade senhorial, oferece a necessária abertura para uma nova consciência, já "limpa" das máculas impostas pela condição submissa.

$\mathrm{Na}$ admoestação dirigida ao senhor no segmento final do poema - "Prepare-se meu senhor" -, parece-me notável o irônico uso do possessivo, que, neste momento, explicita a autonomia alcançada: o tratamento "meu senhor" implica uma inversão da dinâmica de poder, na medida em que a determinação agora decorre daquela que, previamente, ocupara a posição inferior. Ao antes dominador, resta ouvir (e acatar) as demandas de uma mulher já (auto)alforriada, que em tom veemente reclama o direito sobre o próprio corpo - recusando definitivamente o lugar que lhe fora designado perante o desejo senhorial. Para além disso, a subjetividade lírica anuncia o propósito de "gozar", desfrutando "a cama imensa" apropriando-se, por conseguinte, do leito, constituído como espaço destinado ao exercício da vontade do colonizador. À maneira de um arremate, a estância que encerra o poema delineia um projeto existencial: a partir da conquista do tempo e do direito à autodeterminação, a emancipada mulher encontra, finalmente, as possibilidades para "desfrutar do amor", buscando sua realização afetiva.

Um dos poemas que mais explicitamente cantam a experiência erótica no livro é "Eu falo" (SOBRAL, 2017, p. 47):

\author{
Gosto do falo intumescido \\ de um corpo negro com conteúdo \\ que sussurra ao invés de gritar \\ da fala certeira do falo em chamas \\ Gosto do falo a invadir \\ o negrume do espaço entre minhas pernas \\ do falo decorado pelos neurônios \\ Falo sem falácias \\ O falo fica bem na boca \\ É fonte suprema e sagrada refeição
}


Gosto do falo mudo de tesão

A me deixar sem fala.

O que, para uma leitura desatenta, poderia parecer uma espécie de discurso encomiástico falocêntrico se revela, em uma interpretação aprofundada, uma celebração do desejo feminino disposto a reclamar, sem freios, a potência do gozo. Subvertendo topoi que, no ideário racista, atualizam a reificação hipersexualizante, o poema de Cristiane Sobral canta os anseios por um corpo em que a racialização opera como elemento potencializador de sentidos. Isso produz uma inversão nas construções discursivas que reduzem o falo negro a um objeto fetichizado, na medida em que ele se torna a figuração metonímica de uma individualidade reconhecida de modo íntegro. Assim é que o "falo intumescido", signo da sexualidade em sua potência máxima, é desejado a partir de sua relação vinculante ao "corpo negro com conteúdo" - não reduzido, por conseguinte, à condição de fetiche; para esse sentido igualmente concorrem o elogio do sussurro em oposição ao grito - isto é, da expressão afetiva íntima em oposição ao alardeio - e a menção à "fala certeira do falo em chamas" - ou seja, à significância que ultrapassa a facticidade física.

Ao especificar esse modo de relação com o falo negro, a primeira estância do poema estabelece os elementos fundamentais do discurso que se prolongará pelas duas outras estrofes - que consistirão, essencialmente, em variações sobre o mesmo motivo, o que se explica pelos limites impostos a quaisquer tentativas de dizer o gozo: como verbalizar os frêmitos da carne? À luz dessas considerações é que me parece pertinente interpretar a segunda estrofe - passagem crucial por tratar daquele ato que, no discurso racista, será o alvo fulcral da fetichização: a penetração do corpo pelo falo negro. A opção léxica pelo verbo "invadir" enuncia uma subversão desse registro, deslocando-o desde um contexto que originariamente remeteria à desumanização ou à violação para um âmbito de reciprocidade, algo reiterado pela racialização de ambos os corpos - uma vez que o (negro) falo invade o "negrume" entre as pernas. Na última estrofe, a referência à felação produz uma eficaz síntese imagética: por meio de uma intensificação do desejo, a subjetividade lírica emudece o falo, ao mesmo tempo em que este também deixa "sem fala" - consumando um processo dialético em que o silenciamento é imposto a partir da exacerbação dos significados: se os corpos mutuamente se calam, isso ocorre em decorrência de uma ação recíproca ensejada pela conjugação 
de desejos levada ao limite.

Encontramos um registro descritivo semelhante em "Luxúria" (SOBRAL, 2017, p. 48):

\author{
Portas pretas solitárias \\ lambem a rotina \\ lânguidas, femininas \\ com entradas úmidas \\ Portas pretas \\ ainda trancadas \\ convidativas \\ como orquídeas deitadas \\ Línguas negras tesas \\ pincelaram as portas pretas \\ penetraram falanges de dedos \\ escrutinaram o prazer \\ As portas pretas \\ foram visitadas \\ agora grutas molhadas \\ escorrendo o mel da vida.
}

Em contraste com o poema anteriormente analisado - ao qual este se segue, no volume físico, ocupando a página posterior -, essa composição tematiza o corpo feminino, tratado como ente desejante; e, mais uma vez, o estro de Cristiane Sobral se revela afeito à desconstrução de lugares-comuns em torno da corporeidade negra. Se, para o imaginário racista, os corpos de mulheres negras permanecem à disposição dos homens na posição de herdeiros da autoridade senhorial evocada em "Alforria" -, no poema presente em Terra negra, essa disponibilidade cede lugar a uma abertura ao gozo que emerge da própria vontade. Assim é que, conquanto úmidas, as "portas pretas solitárias" permanecem "trancadas", embora propensas ao encontro amoroso; não obstante, a abertura pressupõe um convite - o que enfatiza a reciprocidade como condição imposta.

O último par de estrofes da composição trata de um segundo momento: aquele em que, a partir do estímulo erótico, as "portas pretas" abandonam sua posição passiva - quando permaneciam "como orquídeas deitadas" - e se oferecem às "línguas negras tesas" e às "falanges de 
dedos". Mais uma vez, pode-se perceber um diálogo com "Eu falo", na medida em que a racialização dos corpos opera como acentuação da reciprocidade. Ainda a esse respeito, importa notar a força retórica nítida no arranjo dos versos que abrem os três últimos versos da terceira estância:

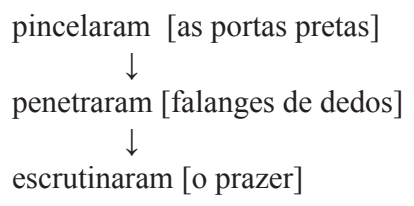

Por conseguinte, o ato da penetração é mais uma vez evocado em um momento específico: aquele subsequente ao movimento erótico inicial, denotado pelas "pinceladas" - ou seja, ao conjunto de estímulos que opera a abertura das "portas pretas" a partir do convite efetivado - que, por sua vez, antecede o derradeiro movimento de exploração (escrutínio) do gozo desejante. Na estância final, a menção às "grutas molhadas" que escorrem "o mel da vida" opera como um fechamento, desvelando a transformação efetivada na superfície corporal a partir da experiência erótica.

Questões não menos instigantes assomam a partir de uma leitura de "Miradouros" (SOBRAL, 2017, p. 51):

Se você puder me ver
além da cor
além do sexo
Verás
Tudo o que tenho
Tudo o que trago
Na alma
Terás que mirar
além do que sou
além do que tenho
Mas só se puder perceber com calma
Pigmentando a sua retina
Eis que me dispo
em pele, alma
e essência.
tom desafiador com que se inicia o poema assinala uma con- 
frontação: a subjetividade lírica desafia o olhar do interlocutor, projetado como uma instância que generifica e racializa o seu corpo desde um ordenamento racista e patriarcal, a despojar-se desses mesmos valores. Consoante o entendimento exposto pelo eu lírico, o atendimento a essa demanda implicaria uma ultrapassagem dos marcadores vinculados àquelas estruturas opressoras, facultando o desvelamento daquilo que tem e traz "na alma" - isto é: de seus atributos mais essenciais. Com poucas variações, a segunda estância retoma o já afirmado na estrofe inicial, inserindo uma nova condição: a exigência da "calma", o que pressupõe um estado anímico particular, e que pode ser interpretado como uma disposição para superar o habitus consolidado.

Não obstante, a última estrofe determina a incorporação de outro elemento: a pigmentação do olhar. O que se torna assim patente é a necessidade de um segundo movimento: uma vez despojado dos valores patriarcais e racistas, é preciso que o olhar se submeta a uma nova racialização, que doravante lhe permita considerar a especificidade do corpo que a ele se apresenta. Vale notar, contudo, que esse processo deve ocorrer em direção contrária à ordem vigente: apenas interpelando-a pode o olhar assumir a modulação necessária para que a percepção se efetive da maneira adequada. Em outras palavras: apenas um olhar enegrecido (porque pigmentado) tem condições de apreciar os atributos particulares de um corpo negro.

Observe-se ainda que os versos finais do poema denotam uma superação do que, a princípio, poderia parecer uma reafirmação da dicotomia corpo/alma - que, na tradição ocidental, constituiu um dos principais fundamentos do ideário racista. Despir um corpo negro não implica recusar sua pigmentação, mas despojá-la do sentido inferiorizante arbitrariamente imposto; pele e alma são, afinal, o mesmo - e a afirmação de sua negritude nada mais é do que o reconhecimento de suas qualidades intrínsecas, para além das significações pejorativas fixadas por instâncias opressoras. Ressalte-se, por fim, que esse gesto escapa à representação típica do imaginário racista e patriarcal, em que o desnudamento do corpo negro feminino evoca imediatamente a dinâmica hipersexualizante. Trata-se, na verdade, do inverso: de um ato que encerra um desvelamento essencial.

"Quem sou eu" possibilita algumas considerações em uma direção próxima (SOBRAL, 2017, p. 62-63):

Se me chamam exótica não respondo aos apelos de: Hei mulata! 
Meu aparelho de surdez

que eu nem uso

está com defeito

Se me chamam morena

uso a meu favor a invisibilidade do sistema

e desapareço

Morena? Sei que não sou

Ouvi linda? Rainha?

Sim

Essa sou eu

Bela como todas as mulheres

que se querem belas

Amo ser quem sou

Se me chamam negra

estou aqui!

Com toda a negritude do meu ser

desfilo com alegria o meu pretume

exibindo para quem quiser ver

na delícia de ser o que sou

Sou negra

Sou mulher

Aqualtune, Nzinga, Dandara

Empoderada ainda por muitas outras

Com orgulho!

A ostensiva recusa da exotificação, manifesta já nos versos que abrem a composição, prolonga-se pelas duas primeiras estrofes. Ao não atender os chamamentos que lhe são dirigidos, efetivados mediante nomes que implicam um apagamento consoante parâmetros racistas, a subjetividade lírica se apodera dos dispositivos de poder, esquivando-se à imposição do assujeitamento. A referência ao inexistente "aparelho de surdez", para além da evidente ironia, sugere uma atitude que promove um necessário confronto, por intermédio de um gesto cínico. Trata-se, em outras palavras, de responder à nomeação com a necessária contundência, o que implica romper o regime de cordialidade instituído como estratégia de domesticação dos corpos negros. A não-resposta e a desaparição constituem, portanto, subterfúgios que possibilitam a desqualificação dos nomes racistas. 
A decisão de atender apenas aos nomes que percebe como adequados é consequência de uma postura política, que se traduz em uma atitude afirmativa: trata-se de não admitir quaisquer modos de designação que concorram para invisibilizar ou reduzir a estereótipos os corpos negros. Em sentido inverso, a decisão de aceitar as designações positivas não deve ser compreendida como expressão de vaidade ou um egocentrismo, visto que também essa disposição encerra um propósito político - sobretudo quando se considera que a beleza de "todas as mulheres", nesse caso específico, diz respeito a um corpo negro; portanto, a um corpo historicamente preterido pelos parâmetros estéticos racialmente estabelecidos. Reclamar o direito de declarar-se bela pressupõe uma extensão dessa exigência para todos os corpos negros. Destarte, uma forçosa revisão dos preceitos instituídos a partir do ordenamento racista - possibilitando uma abertura para o amor-próprio reiteradamente negado ao povo negro.

Nas duas últimas estrofes, tem lugar o momento culminante de todo esse processo: a referência ao nome reconhecido como prioritário pela subjetividade poética - que, ao ser chamada "negra", reconhece a mais pertinente evocação de sua presença. A esse respeito, importa observar o segundo verso: dizer "estou aqui", em resposta ao chamamento, significa reconhecer uma determinação de seu lugar no mundo; quer dizer: para o eu lírico, existir é ser negra - de modo que essa nomeação mobiliza o que essencialmente a constitui. Disso decorre o desígnio de não ocultar essa qualidade fundamental: ao ostentar a negritude do seu ser, ao desfilar seu pretume, ao exibir-se, a subjetividade poética subverte radicalmente as imposições que almejavam seu ocultamento.

Por fim, a última estrofe enseja uma recuperação do sentido histórico desse ato de afirmação. Cabe não olvidar que também os dispositivos opressores têm sua própria historicidade; em outras palavras, que eles não existiram desde sempre enquanto tais, uma vez que sua instituição - bem como sua viabilização e sua reiterada legitimação - foi propiciada por um conjunto de circunstâncias sociais, culturais e políticas. Por conseguinte, o resgate de um momento anterior à emergência dessas condições faculta a possibilidade concreta da construção de uma realidade outra, ancorada em figuras históricas que resistiram aos processos de assujeitamento. Dizer-se negra e mulher sob a evocação de Aqualtune, Nzinga e Dandara significa reconhecer uma via para, como elas, constituir-se como instância particular de resistência. 
Encerro este ensaio com alguns breves comentários sobre "Papo reto" (SOBRAL, 2017, p. 65-66):

Sou preta guerreira

Defendo um escurecimento necessário

com a minha carapinha

Vou matando a erva daninha

Papo reto

$\mathrm{O}$ meu cabelo toca o teto

O poder

É preto

Sou rainha!

Dandara.com

Nossos filhos estão na escola

Muito além de jogar bola

Tomam conta do pedaço

Porque é nosso

o poder pra vencer

Atenção secretárias do lar!

Vamos parar

Tô gargalhando aqui

O Brasil vai se enrolar

Não saí da senzala

apenas para limpar sua sala

Nossa hora vai chegar

Papo reto

$\mathrm{O}$ meu cabelo toca o teto

O poder é preto

Com a minha carapinha

Vou matando erva daninha

Sou rainha

Dandara.com

Sou preta guerreira

Defendo um escurecimento necessário

tiro qualquer racista do armário

Enfio o pé na porta da casa grande

E entro.

Ao assumir-se, já no verso de abertura, como "preta guerreira", a subjetividade lírica atribui a si mesma uma dupla qualificação - aludindo, 
por um lado, à sua condição racializada; e, por outro lado, à sua propensão para o confronto. Se a racialização resulta de uma determinação imposta por um ordenamento politicamente instituído a partir de estruturas culturais, sociais e históricas, a disposição para o enfrentamento pode ser entendida como uma reação decorrente daquela determinação. Desse modo, a combatividade assoma como efeito do enegrecimento - portanto, como forma de resistência contra o ordenamento racializante.

O sentido da confrontação é explicitado no restante da primeira estrofe, em que o eu lírico delineia seu planejamento estratégico - já enunciado, de maneira sintética, no segundo verso: ao evocar um "escurecimento necessário", a subjetividade lírica expõe seu propósito de subverter o mundo em sua figuração atual, ou seja: enquanto uma realidade erigida a partir de valores e dispositivos racistas. O instrumento que tornará possível concretizar esse intento subversivo está presente no próprio corpo da "preta guerreira": o seu cabelo - sua "carapinha" que "toca o teto". No desfecho dessa estância, a referência ao black power e ao imaginário endereço na internet ("Dandara.com") perfazem a correlação entre o movimento de afirmação política do povo preto e seus desdobramentos na contemporaneidade.

A segunda e a terceira estâncias descrevem como esse projeto de subversão tem lugar no presente - por intermédio de uma nova geração de crianças negras que, pela via da escolarização, ultrapassam os lugares que lhes são prescritos pelo ideário racista, já precocemente ocupando as posições de poder; e pela convocação das "secretárias do lar", a fim de que participem da mobilização política - e se prolongará no futuro, fazendo chegar a "hora"; isto é: o decisivo momento da ação revolucionária efetivada por aquele povo que não deixou a senzala para conformar-se à subalternidade.

Nas duas estrofes que encerram a composição, a primeira estância é retomada, embora com pequenas alterações; retoricamente, pode-se nisso perceber uma reiteração do discurso de enfrentamento - o "papo reto" mencionado já no título -, cujo desígnio é evidenciado pelos versos que arrematam o poema: desmascarar todos os que sustentam os dispositivos opressores (o que significa: forçá-los a se revelarem como os inimigos a serem combatidos) e invadir a casa grande: o símbolo maior da privilegiada posição ocupada pelos senhores/colonizadores.

A modo de conclusão, parece-me importante observar que Terra negra se inscreve na produção literária de Cristiane Sobral como desdo- 
bramento de uma obra em que assomam a organicidade e consistência, sobretudo no que tange à construção de um projeto estético atento a demandas urgentes das mulheres negras. A esse propósito, a posição fulcral ocupada pela afetividade e pelo erotismo na referida coletânea poética alerta para a urgência dessas questões no processo emancipatório: trata-se, ainda, de confrontar valores e estereótipos racistas, libertando os corpos negros e propiciando a construção de um espaço próprio - uma "terra negra" - em que o desejo possa manifestar-se em toda a plenitude.

\section{REFERÊNCIAS}

ALIGHIERI, Dante. Vita nuova. Trad. Mark Musa. Bloomington: Indiana University Press, 1973.

CUTI. Literatura negro-brasileira. São Paulo: Selo Negro, 2010.

FERREIRA, Vera Lúcia da Silva Sales. Cristiane Sobral. In: DUARTE, Eduardo de Assis (org.). Literatura e afrodescendência no Brasil: antologia crítica. v. 3: contemporaneidade. Belo Horizonte: UFMG, 2014.

KINTÊ, Akins; CUTI. Pretumel de chama e gozo: antologia da poesia negro-brasileira erótica. São Paulo: Ciclo Contínuo, 2015.

PLATÃO. Banquete. In: GARRIDO, Manuel (ed.). . Los diálogos eróticos: Banquete y Fedro. Trad. Manuel Sacristán. Madrid: Tecnos, 2013. SOBRAL, Cristiane. Terra negra. Rio de Janeiro: Malê, 2017.

Recebido em: 30/04/2019

Aceito em: 30/09/2019 